\title{
Disialo-trisialo bridging of transferrin is due to increased branching and fucosylation of the carbohydrate moiety
}

\author{
Eva Landberg, Eva Åström, Bertil Kågedal and Peter Påhlsson
}

\section{Linköping University Post Print}

\section{Tweet}

N.B.: When citing this work, cite the original article.

Original Publication:

Eva Landberg, Eva Åström, Bertil Kågedal and Peter Påhlsson, Disialo-trisialo bridging of transferrin is due to increased branching and fucosylation of the carbohydrate moiety, 2012, Clinica Chimica Acta, (414), 58-64.

http://dx.doi.org/10.1016/j.cca.2012.07.026

Copyright: Elsevier http://www.elsevier.com/

Postprint available at: Linköping University Electronic Press http://urn.kb.se/resolve?urn=urn:nbn:se:liu:diva- 88368 


\section{Disialo-trisialo bridging of transferrin is due to increased branching and fucosylation of the carbohydrate moiety}

Eva Landberg ${ }^{\mathrm{a}^{*}}$, Eva Åström ${ }^{\mathrm{b}}$, Bertil Kågedal ${ }^{\mathrm{c}}$ and Peter Påhlsson ${ }^{\mathrm{b}}$

${ }^{a}$ Division of Clinical Chemistry, Department of Clinical and Experimental Medicine, Faculty of Health Sciences, Linköping University, County Council of Östergötland, Linköping, Sweden, ${ }^{b}$ Division of Cell Biology, Department of Clinical and Experimental Medicine, Linköping University, S-58185 Linköping, Sweden, ${ }^{\mathrm{c}}$ Division of Clinical Chemistry, Department of Clinical and Experimental Medicine, Linköping University, Linköping, Sweden.

Running head: Di-tri bridging is due to altered glycosylation

Keywords: transferrin, CDT, di-tri bridging, glycosylation, liver disease

*Corresponding author

Eva Landberg

Division of Clinical Chemistry

University Hospital

S-581 85 Linköping

Sweden

Phone: +46101033226

Fax: +46101033206

E-mail: eva.landberg@lio.se 


\section{Abstract}

Background: Carbohydrate deficient transferrin (CDT) is used for detection of alcohol abuse and follow-up. High performance liquid chromatography (HPLC) of transferrin glycoforms is highly specific for identification of alcohol abuse, but unresolved disialo- and trisialotransferrin glycoforms sometimes makes interpretation difficult. The cause of this phenomenon is unknown, cannot be explained by genetic variants of transferrin, but seems to be associated with liver disease.

Methods: Nineteen serum samples showing di-tri bridging when analyzed by HPLC were collected. Transferrin was purified by affinity chromatography, and N-linked oligosaccharides were released enzymatically. The $\mathrm{N}$-glycans were further analyzed by high performance anion-exchange chromatography with pulsed amperometric detection and MALDI-TOF mass spectrometry.

Results: The HPLC-analysis showed three different types of glycoform patterns. The Nglycans from fifteen samples showed patterns with increased number of triantennary structures containing one or two fucose residues. One sample contained an increased amount of triantennary glycans without fucose. Three samples showed a glycosylation pattern similar to normal transferrin.

Conclusions: The di-tri bridging phenomenon was associated with alterations in transferrin glycosylation in the majority of cases. Transferrin contained a higher extent of triantennary and often fucosylated $\mathrm{N}$-linked oligosaccharides. These results may be important in future diagnostic approaches to liver diseases. 


\section{Introduction}

Human transferrin is a globular protein responsible for iron transport in plasma. It is composed of a single polypeptide chain of 679 amino acids arranged in two independent metal ion-binding globular domains. It has two main glycosylation sites at Asn-413 and Asn611[1]. The oligosaccharides found on these sites are mainly bi- and triantennary complex type glycans with terminal sialic acid [2-4]. Normal human serum typically contains a major transferrin glycoform containing two biantennary N-glycans with a total number of four sialic acid residues (tetrasialotransferrin), and minor isoforms with two (disialotransferrin), three (trisialotransferrin), and five (pentasialotransferrin) sialic acid residues.

Chronic heavy alcohol drinking alters the transferrin glycoform pattern so that the disialoisoform increases and asialoisoforms may appear [5-8]. These isoforms lack one or both of the carbohydrate chains $[9,10]$ and are collectively denoted carbohydrate deficient transferrin (CDT). Among several laboratory tests routinely used in clinical and forensic medicine, the percentage of CDT of total transferrin (\% CDT) is considered the most specific biochemical marker for detecting chronic alcohol abuse and for monitoring abstinence during treatment $[6,11,12]$.

A number of methods have been applied for CDT quantification including immunometric, electrophoretic, chromatographic and mass-spectrometric methods. High performance liquid chromatography (HPLC) of transferrin glycoforms was recommended as the interim reference method to be applied in CDT confirmatory analysis [13]. To overcome the lack of standardization affecting CDT analysis, the Working Group on Standardization of CDT measurement (IFCC-WG-CDT) suggested to use disialotransferrin as the primary target molecule for CDT measurement, expressed as relative amount of total transferrin concentration $[13,14]$. Although there are great advantages of this method, in particular 
regarding analytical and clinical specificity, a number of atypical separation patterns, not reflecting alcohol abuse, have been identified. Atypical patterns are often attributed to genetic transferrin variants of the amino acid sequence such as BC or CD [15]. In addition, there are also cases with a chromatographic pattern where disialo- and trisialotransferrin are not adequately separated. This phenomenon is called disialo-trisialo bridging (di-tri bridging) [16]. Presence of di-tri bridging makes the interpretation of CDT difficult and increases the uncertainty of the measurement. It was recently established that the di-tri bridging phenomenon could neither be explained by a genetic transferrin protein variant nor by an increased trisialotransferrin fraction [16]. It has been suggested that the di-tri bridging phenomenon may be prevalent in patients with liver cirrhosis or other severe liver abnormalities [16, 17].

The aim of this study was to examine if altered glycosylation of transferrin may explain the occurrence of a di-tri bridging pattern on HPLC. 


\section{Material and methods}

\subsection{Patients and serum samples}

During a period of six months, serum samples admitted to the laboratory for routine analysis of CDT were selected for further analysis if the chromatogram indicated presence of di-tri bridging. Data on age, gender and plasma liver enzymes ( $\gamma$ Glutamyl transferase $(\gamma \mathrm{GT})$, Alanine aminotransferase (ALT) and Aspartate aminotransferase (AST)) were collected from the laboratory data system. The patient identity of each sample was then removed (Table 1). CDT was analyzed by high-performance liquid chromatography as previously described [18]. The control samples consisted of one serum pool from 150 patients with normal CDT values and one pool from 150 patients with increased CDT (> $3 \%)$. The controls were analyzed in each run. Nineteen plasma samples that showed di-tri bridging were identified and stored at $-20{ }^{\circ} \mathrm{C}$ until further analysis.

\subsection{Chemicals and reagents}

Human transferrin from Sigma (Holo-transferrin, iron-saturated, T3400 Sigma-Aldrich) was used as reference (reference transferrin). All water solutions were prepared with Milli Q Water. All chemicals were from Merck except for glycine, Triton-X100, BSA, AGP and $\mathrm{KH}_{2} \mathrm{PO}_{4}$ (Sigma-Aldrich), SDS and $\beta$-mercaptoethanol (Bio-Rad Laboratories).

\subsection{Purification of transferrin}

Transferrin was isolated from serum samples using affinity chromatography. Transferrin specific antibodies (Rabbit anti-human transferrin, A0061, DAKO) were immobilized on a 5 
ml HiTrap NHS-activated column (Amersham Biosciences) according to the manufacturer's instructions. The column was connected to an ÄKTA prime instrument equipped with a UV detector (Amersham Bioscience). Chromatography was performed at a flow rate of 1.0 $\mathrm{ml} / \mathrm{min}$. Serum was diluted twofold with phosphate buffered saline, $\mathrm{pH} 7.4$ (PBS), and after equilibration of the column with 2 column volumes of PBS, the diluted serum sample was injected. Unbound proteins were eluted with $30 \mathrm{ml}$ of PBS. The absorbance of the effluent was recorded at $280 \mathrm{~nm}$. Transferrin was eluted using $0.2 \mathrm{M}$ glycine-HCl buffer, $\mathrm{pH}$ 2.0, and collected in 1-ml fractions. The fractions were immediately neutralized with phosphate buffer, $0.5 \mathrm{M}, \mathrm{pH} 8$, and fractions containing transferrin were pooled and stored at $-20^{\circ} \mathrm{C}$. Transferrin concentration in serum samples was determined by an immunonephelometric method on BN ProSpec (Siemens Healthcare Diagnostics, Deerfield, IL, USA). The calibrator was traceable to CRM 470. Transferrin concentration in purified samples was determined using the bicinchoninic acid assay (BCA Protein Assay Reagent, Pierce Biotechnology) using reference transferrin (Sigma-Aldrich, see also 2.2) as a standard. According to the manufacturer this standard was $98 \%$ pure.

\subsection{Sodium dodecyl sulfate polyacrylamide gel electrophoresis}

Purified transferrin was analyzed by SDS-PAGE on $10 \%$ Tris- $\mathrm{HCl}$ gels (Bio-Rad) under denaturing conditions according to Laemmli [19]. Bands were visualized using Coomassie blue staining.

\subsection{Release of glycans from transferrin}


The transferrin samples were dialyzed against $3 \times 2$ of water for $20 \mathrm{~h}$ at $4{ }^{\circ} \mathrm{C}$ (Spectra/Por Dialysis membrane, Spectrum Laboratories, MWCO: 12-14 000) and lyophilized. From each sample $250 \mu \mathrm{g}$ transferrin was dissolved in $180 \mu \mathrm{l}$ of phosphate buffer $(0.05 \mathrm{M}$, $\mathrm{pH}$ 7.5). Then $20 \mu \mathrm{l}$ denaturizing solution ( $1 \%$ SDS, containing $1 \mathrm{M} \beta$-mercaptoethanol) was added. After boiling the samples for $5 \mathrm{~min}$ in a water bath and cooling to room temperature, $20 \mu \mathrm{l}$ of $10 \%$ Triton X-100 (Sigma-Aldrich) and $2 \mu \mathrm{l}(1 \mathrm{U})$ of Peptide-N-glycosidase F (PNGase F, Sigma-Aldrich) was added and the samples were incubated for $20 \mathrm{~h}$ at $37{ }^{\circ} \mathrm{C}$. After cooling of the samples to room temperature, $20 \mu 1$ of $5 \%$ acetic acid was added and the samples were incubated for $2 \mathrm{~h}$ at room temperature.

\subsection{Purification of released oligosaccharides}

Sep-Pak C18 cartridges (Waters Corporation) were pre-conditioned with $10 \mathrm{ml}$ methanol followed by $10 \mathrm{ml}$ of water. The samples were applied, eluted with $1 \mathrm{ml}$ of water and lyophilized. The lyophilized samples were dissolved in $100 \mu \mathrm{l}$ of water and applied to columns containing Bio Gel P2 (2 ml, extra fine, Bio-Rad). Five hundred micro litres of water was applied to the column, before the desalted transferrin oligosaccharides were recovered by elution with $0.6 \mathrm{ml}$ of water and lyophilized.

2.7 Analysis of oligosaccharides by high performance anion exchange chromatography with pulsed amperometric detection (HPAEC-PAD).

Analysis of released oligosaccharides was performed using a ISC-3000 HPAEC-PAD-system (Dionex) equipped with a CarboPac PA200 column at a flow rate of $0.5 \mathrm{ml} / \mathrm{min}$ [20]. Chromatography was performed using a constant concentration of $0.1 \mathrm{M} \mathrm{NaOH}$ and a two 
step gradient of sodium acetate ( $\mathrm{NaOAc}$ ) as indicated in Table S1 (supplementary data). The lyophilized samples were dissolved in $100 \mu \mathrm{l}$ of water. Injection volume was $20 \mu 1$.

\subsection{Mass spectrometry}

Mass spectra were acquired in linear mode on a Voyager-DE Pro instrument (Applied Biosystems) equipped with a nitrogen laser. Oligosaccharide samples were converted to ammonium form by passage through a miniaturized column of cation-exchange resin $\mathrm{AG}$ 50W-X4, 200 mesh (0.3 ml, Bio-Rad), previously equilibrated with a $5 \%$ ammonium hydroxide solution. Glycans were eluted with water and lyophilized.

Samples were dissolved in a few micro liters of water, and an equal volume of 2', 4', 6’trihydroxy-acetophenone (THAP) in acetonitrile/20mM ammonium citrate (50/50) was used as matrix solution [21]. After drying, recrystallisation from ethanol was performed prior to analysis. Analysis was performed in the negative-ion mode using delayed extraction (180 nsec) and an acceleration voltage of $20 \mathrm{kV}$.

Desialylation of oligosaccharides was performed by incubation with $2 \mathrm{M}$ acetic acid at $80{ }^{\circ} \mathrm{C}$ for $3 \mathrm{~h}$ [22]. The sample was applied to a miniaturized column containing a mixed ion exchange resin (AG50W X4, $\mathrm{NH}_{4}{ }^{+}$-form and $\mathrm{AG} 2-\mathrm{X}, \mathrm{Cl}^{-}$-form, Bio-Rad). Oligosaccharides were eluted with water and lyophilized. The desialylated oligosaccharides were analyzed in the positive-ion mode using the THAP matrix. 


\section{Results}

Serum samples were collected on the basis of an abnormal transferrin isoform pattern (so called di-tri bridging), obtained by the routine HPLC method. The criteria for di-tri bridging consisted of poor resolution of di- and trisialotransferrin (no base-line separation) together with a shortened retention time of the trisialotransferrin peak as compared to the trisialotransferrin peak in the control sample run in the same analytical sequence (Fig.1). Nineteen samples with di-tri bridging were collected over a period of six months. During this period a total of 2246 CDT-samples were admitted to the laboratory. Thus, the frequency of di-tri bridging was $0.8 \%$. The mean percentage of trisialotransferrin was $7.5 \%$ (range: $3.6-$ $13.6 \%$ ), which was higher than the $4.6 \%$ trisialotransferrin found in the serum pool from patients with increased CDT. Fifteen of the samples showed a chromatogram consistent with the profile shown in Figure 1A (transferrin glycoform pattern - 1 (TGP-1)). All of these patients had increased levels of one or several liver enzymes (Table 1). Three samples with di-tri bridging showed a pattern where not only trisialotransferrin, but also tetrasialotransferrin eluted earlier than the control (TGP-2). In contrast to patients with TGP1, the patients with TGP-2 all had normal levels of liver enzymes (Table 1). One sample with di-tri bridging showed a HPLC chromatogram with increased penta- and hexasialotransferrin compared to the other samples with di-tri bridging (TGP-3, Fig. 1C).

Transferrin was isolated from patients' serum samples by affinity chromatography. Recovery of transferrin from the serum samples was in the range of 85$100 \%$ (mean 93\%). The purified samples were analyzed by SDS-PAGE and found to be $>95$ $\%$ pure as judged by Coomassie blue staining. $\mathrm{N}$-glycans were then enzymatically released from the affinity-purified and denatured transferrin and SDS-PAGE analysis showed one band with a molecular weight of approximately $4 \mathrm{kDa}$ less than native transferrin, indicating 
complete removal of both N-glycans (Fig. S1, lane 3, supplementary data). The SDS-PAGE analysis revealed that it was essential to denature transferrin prior to enzymatic digestion to obtain a fully deglycosylated protein. Enzymatic digestion of transferrin without prior denaturation resulted in a reduction of molecular weight of only $2 \mathrm{kDa}$, indicating removal of only one N-glycan (Fig. S1, lane 2). HPAEC-PAD analysis of oligosaccharides released from reference transferrin showed a major peak eluting at 34 min, representing a biantennary disialylated glycan (Fig. S2A, supplementary data). Peaks corresponding to biantennary monosialylated glycans and di- and trisialylated triantennary glycans could also be identified and were tentatively assigned according to previous studies [9]. Transferrin from the serum pool with increased CDT (150 samples) but without di-tri bridging was also examined. Released oligosaccharides were analyzed by HPAEC-PAD and showed a profile identical with that of the reference transferrin (Fig. S2B).

HPAEC-PAD analysis of oligosaccharides released from the 15 samples with TGP-1 all showed chromatograms with several additional peaks compared to reference transferrin (denoted as peak 1-7 in Fig. S2C). A majority of these peaks had retention times between 15 and 32 minutes and thus eluted earlier than the major biantennary, disialylated glycan. It is known that fucose containing $\mathrm{N}$-glycans have reduced retention times compared to corresponding non-fucosylated glycans in the HPAEC-PAD analysis thus, the additional peaks most likely represent fucosylated forms of biantennary and triantennary glycans [2325]. Furthermore, most TGP-1 samples showed an increase in intensity and number of peaks eluting later than the major biantennary, disialylated glycan (between 35 and 50 min, Fig. S2C), indicating an increase in non-fucosylated triantennary structures.

HPAEC-PAD analysis of the tree samples with TGP-2 (Fig. S2D) showed only minor differences and no additional peaks compared to the serum pool from patients without di-tri bridging and reference transferrin. HPAEC-PAD analysis of the sample with TGP-3 
(Fig. S2E) showed a marked increased intensity of peaks eluting later in the chromatogram (between 35 and $50 \mathrm{~min}$ ), corresponding to non-fucosylated triantennary structures. In contrast to the TGP-1 samples the TGP-3 sample did not show any additional peaks eluting between 15 and $32 \mathrm{~min}$.

To further characterize the additional glycans that appeared in the HPAEC analysis of the di- tri bridging samples, the released oligosaccharides were analyzed by MALDI-TOF mass spectrometry (Fig. 2). A spectrum of oligosaccharides released from reference transferrin showed prominent $[\mathrm{M}-1]^{-}$-ions corresponding to monosialylated and disialylated biantennary glycans, and minor peaks representing mono-, di- and trisialylated triantennary structures. In addition minor peaks representing fucosylated glycans were also present. This glycosylation pattern is consisten with previous studies [10, 26, 27]. Mass spectrometric analysis of oligosaccharides released from a TGP-1 sample showed, in addition to ions corresponding to the mono- and disialylated biantennary glycans, a number of ions corresponding to triantennary glycans (Fig. 2B). The mass spectra also revealed presence of mono- and difucosylated glycans. Oligosaccharides from the same TGP-1 sample were desialylated and analyzed again by MALDI-TOF mass spectrometry (Fig. 2C). The resulting $[\mathrm{M}+\mathrm{Na}]^{+}$- ions correspond to bi- or triantennary glycans with 0-2 fucose moieties. Taken together, the HPAEC analysis and mass spectrometry data indicate the presence of more branched and fucosylated oligosaccharides in transferrin from TGP-1 patient samples. Mass spectrometric analysis of released glycans from the TGP-2 samples showed no major differences as compared to reference transferrin (Fig. 2D), whereas the TGP-3 sample showed the same increase in triantennary glycans as in the TGP-1 sample. However in contrast to the TGP-1 sample there were no peaks corresponding to fucosylated glycans. 


\section{Discussion}

The di-tri bridging phenomenon is occasionally observed in the routine analysis of CDT by HPLC or capillary electrophoresis. In this study the di-tri bridging phenomenon was found in a frequency of $0.8 \%$, which is similar to previous findings by Helander et al. [15] who reported a di-tri bridging frequency of $0.6 \%$ in routine samples. It has been shown that the ditri bridging phenomenon is not specifically linked to genetic variants of transferrin, since the pattern is observed also in patients with the most commonly observed homozygous transferrin C1 variant [16].

We isolated transferrin from patients with a di-tri bridging phenomenon observed by HPLC. Fifteen of the 19 samples showed an HPLC glycoform pattern with unaltered retention times of tetra, penta and hexasialotransferrin glycoforms compared to reference transferrin (TGP-1). When the released transferrin glycans from these samples were analyzed by HPAEC strikingly similar chromatograms were obtained showing several extra peaks compared to normal transferrin and transferrin from patients with increased CDT. Increased fucosylation was indicated in the HPAEC profile, in that most extra peaks eluted earlier than the major disialo biantennary glycan. Presence of fucose residues are known to decrease the retention time of glycans on $\operatorname{HPAEC}[24,25]$. A partial structural characterization of the additional oligosaccharides by MALDI-TOF mass spectrometry confirmed an increase in oligosaccharide branching and fucosylation.

In three of the samples with di-tri bridging we found an aberrant pattern in the separation of glycoforms by HPLC, where the retention time of the peak corresponding to tetrasialotransferrin and pentasialotransferrin eluted somewhat earlier compared to normal (TGP-2). Analysis of released glycans from these samples revealed a glycosylation pattern very similar to reference transferrin and the pool without di-tri bridging. Since the retention 
time of all glycoforms was slightly affected in these samples, it can not be excluded that a genetic alteration in the transferrin protein caused the di-tri bridging phenomenon in these cases. It is possible that this is the same pattern as observed by Helander et al [15].

One of the samples with di-tri bridging also showed another type of glycoform pattern by HPLC consisting of an increased percentage of penta- and hexasialotransferrin glycoforms (TGP-3). This sample showed an altered glycosylation profile mainly by having increased branching of the glycan structures but without increase in fucosylation. This result indicates that an increase in triantennary structures on transferrin may be the major cause of the di-tri bridging phenomenon. This is also consistent with the finding that fucosylated and nonfucosylated pentasialotransferrin are not separated by HPLC [27].

Altered glycosylation of plasma proteins is a common finding associated with liver diseases, including cirrhosis, cancer and hepatitis [26, 28-34]. An increase in branching and fucosylation of transferrin N-glycans has previously been reported in patients with hepatocellular carcinoma $[26,32,34]$, which was similar to the pattern found in the samples with di-tri bridging.

As previously observed by Arndt et al. [16], we found the di-tri-bridging phenomenon to be associated with an increase in trisialotransferrin. The increase of trisialotransferrin did however not correlate to an increase in disialotransferrin (CDT). Thus it is not likely that the increase of trisialotransferrin is caused by alcohol per se [15]. An increased percentage of trisialotransferrin was recently observed in patients with hepatocellular cancer [35]. However, the occurrence of di-tri bridging was not reported.

The retention time of trisialotransferrin was significantly affected in samples with di-tri bridging. This could be explained by the altered glycosylation and increased heterogeneity of glycan structures found in this study. However, it is somewhat surprising that it is only the retention time of trisialotransferrin that is affected and not the retention times of 
other transferrin glycoforms. The trisialo glycoform may contain a greater variety of glycan structures caused by a combination of increased fucosylation and branching, decreased sialylation and less occupancy of one of the glycosylation sites. It is also possible that the increased heterogeneity is more prominent in one of the glycosylation sites and therefore has a greater effect on the separation of glycoforms lacking one of its $\mathrm{N}$-glycans. In a study on site-specific glycosylation of transferrin it was shown that Asn-611 showed a greater variability in N-glycan structures than Asn-413 in normal transferrin [36]. A third, lowoccupancy, glycosylation site at Asn-472 has also been identified [37] and thus, another explanation for the abnormal glycosylation profile may be an increased occupancy of the third glycosylation site in transferrin.

\section{Conclusions}

Our study shows that the di-tri bridging phenomenon found occasionally in CDT measurement by HPLC is associated with alterations in transferrin glycosylation in the majority of cases. Transferrin from these samples contains a higher extent of triantennary and often fucosylated $\mathrm{N}$-linked oligosaccharides. Further studies are needed to examine these glycosylation changes in relation to liver disease of different aetiology. These results may also be applicable in future diagnostic approaches to liver diseases. 


\section{Acknowledgements}

We thank Louise Balla, Dženeta Nezirević Dernroth and Paula Werdina for technical help.

This work was supported with grants from the Medical Research Council of Southeast

Sweden. 


\section{References}

[1] MacGillivray RT, Mendez E, Shewale JG, Sinha SK, Lineback-Zins J, Brew K. The primary structure of human serum transferrin. The structures of seven cyanogen bromide fragments and the assembly of the complete structure. J Biol Chem 1983; 258:3543-3553. [2] Spik G, Bayard B, Fournet B, Strecker G, Bouquelet S, Montreuil J. Studies on glycoconjugates. LXIV. Complete structure of two carbohydrate units of human serotransferrin. FEBS Lett 1975; 50:296-299.

[3] Spik G, Debruyne V, Montreuil J, van Halbeek H, Vliegenthart JF. Primary structure of two sialylated triantennary glycans from human serotransferrin. FEBS Lett 1985; 183:65-69. [4] de Jong G, van Dijk JP, van Eijk HG. The biology of transferrin. Clin Chim Acta 1990; 190:1-46.

[5] Vesterberg O, Petren S, Schmidt D. Increased concentrations of a transferrin variant after alcohol abuse. Clin Chim Acta 1984; 141:33-39.

[6] Arndt T. Carbohydrate-deficient transferrin as a marker of chronic alcohol abuse: a critical review of preanalysis, analysis, and interpretation. Clin Chem 2001; 47:13-27.

[7] Bortolotti F, De Paoli G, Tagliaro F. Carbohydrate-deficient transferrin (CDT) as a marker of alcohol abuse: a critical review of the literature 2001-2005. J Chromatogr B Analyt Technol Biomed Life Sci 2006; 841:96-109.

[8] Stibler H. Carbohydrate-deficient transferrin in serum: a new marker of potentially harmful alcohol consumption reviewed. Clin Chem 1991; 37:2029-2037.

[9] Landberg E, Påhlsson P, Lundblad A, Arnetorp A, Jeppsson JO. Carbohydrate composition of serum transferrin isoforms from patients with high alcohol consumption. Biochem Biophys Res Commun 1995; 210:267-274. 
[10] Flahaut C, Michalski JC, Danel T, Humbert MH, Klein A. The effects of ethanol on the glycosylation of human transferrin. Glycobiology 2003; 13:191-198.

[11] Golka K, Wiese A. Carbohydrate-deficient transferrin (CDT)--a biomarker for long-term alcohol consumption. J Toxicol Environ Health B Crit Rev 2004; 7:319-337.

[12] Salaspuro M. Carbohydrate-deficient transferrin as compared to other markers of alcoholism: a systematic review. Alcohol 1999; 19:261-271.

[13] Jeppsson JO, Arndt T, Schellenberg F, et al. Toward standardization of carbohydratedeficient transferrin (CDT) measurements: I. Analyte definition and proposal of a candidate reference method. Clin Chem Lab Med 2007; 45:558-562.

[14] Helander A, Wielders JP, Jeppsson JO, et al. Toward standardization of carbohydratedeficient transferrin (CDT) measurements: II. Performance of a laboratory network running the HPLC candidate reference measurement procedure and evaluation of a candidate reference material. Clin Chem Lab Med 2010; 48:1585-1592.

[15] Helander A, Eriksson G, Stibler H, Jeppsson JO. Interference of transferrin isoform types with carbohydrate-deficient transferrin quantification in the identification of alcohol abuse. Clin Chem 2001; 47:1225-1233.

[16] Arndt T, van der Meijden BB, Wielders JP. Atypical serum transferrin isoform distribution in liver cirrhosis studied by HPLC, capillary electrophoresis and transferrin genotyping. Clin Chim Acta 2008; 394:42-46.

[17] Stewart SH, Comte-Walters S, Bowen E, Anton RF. Liver disease and HPLC quantification of disialotransferrin for heavy alcohol use: a case series. Alcohol Clin Exp Res 2010; 34:1956-1960.

[18] Helander A, Husa A, Jeppsson JO. Improved HPLC method for carbohydrate-deficient transferrin in serum. Clin Chem 2003; 49:1881-1890. 
[19] Laemmli UK. Cleavage of structural proteins during the assembly of the head of bacteriophage T4. Nature 1970; 227:680-685.

[20] Hermentin P, Witzel R, Vliegenthart JF, Kamerling JP, Nimtz M, Conradt HS. A strategy for the mapping of $\mathrm{N}$-glycans by high-pH anion-exchange chromatography with pulsed amperometric detection. Anal Biochem 1992; 203:281-289.

[21] Papac DI, Wong A, Jones AJ. Analysis of acidic oligosaccharides and glycopeptides by matrix-assisted laser desorption/ionization time-of-flight mass spectrometry. Anal Chem $1996 ; 68: 3215-3223$.

[22] Varki A, Diaz S. The release and purification of sialic acids from glycoconjugates: methods to minimize the loss and migration of O-acetyl groups. Anal Biochem 1984; 137:236-247.

[23] Gohlke M, Blanchard V. Separation of N-glycans by HPLC. Methods Mol Biol 2008; 446:239-254.

[24] Hardy MR, Townsend RR. Separation of fucosylated oligosaccharides using high-pH anion-exchange chromatography with pulsed-amperometric detection. Carbohydr Res 1989; 188:1-7.

[25] Basa LJ, Spellman MW. Analysis of glycoprotein-derived oligosaccharides by high-pH anion-exchange chromatography. J Chromatogr 1990; 499:205-220.

[26] Yamashita K, Koide N, Endo T, Iwaki Y, Kobata A. Altered glycosylation of serum transferrin of patients with hepatocellular carcinoma. J Biol Chem 1989; 264:2415-2423. [27] Oberrauch W, Bergman AC, Helander A. HPLC and mass spectrometric characterization of a candidate reference material for the alcohol biomarker carbohydrate-deficient transferrin (CDT). Clin Chim Acta 2008; 395:142-145.

[28] Mehta A, Block TM. Fucosylated glycoproteins as markers of liver disease. Dis Markers $2008 ; 25: 259-265$. 
[29] Sathish Kumar N, Eapen CE, Jeyamani R, Balasubramanian KA. Serum and urinary fucose concentrations in hepatitis B-related cirrhosis and acute liver diseases. Clin Chim Acta 2004; 342:233-235.

[30] Zhang S, Shu H, Luo K, et al. N-linked glycan changes of serum haptoglobin beta chain in liver disease patients. Mol Biosyst 2011; 7:1621-1628.

[31] Comunale MA, Rodemich-Betesh L, Hafner J, et al. Linkage specific fucosylation of alpha-1-antitrypsin in liver cirrhosis and cancer patients: implications for a biomarker of hepatocellular carcinoma. PLoS One 2010; 5:e12419.

[32] Naitoh A, Aoyagi Y, Asakura H. Highly enhanced fucosylation of serum glycoproteins in patients with hepatocellular carcinoma. J Gastroenterol Hepatol 1999; 14:436-445.

[33] Rydén I, Påhlsson P, Lindgren S. Diagnostic accuracy of alpha(1)-acid glycoprotein fucosylation for liver cirrhosis in patients undergoing hepatic biopsy. Clin Chem 2002; 48:2195-2201.

[34] Matsumoto K, Maeda Y, Kato S, Yuki H. Alteration of asparagine-linked glycosylation in serum transferrin of patients with hepatocellular carcinoma. Clin Chim Acta 1994; 224:1-8. [35] Gressner OA, Jafari S, Erkens M, Gao C, Stanzel S, Gressner AM. Evaluation of serum percent trisialotransferrin as potential predictive biomarker of hepatocellular dedifferentiation in chronic liver disease. Clin Chim Acta 2009; 403:188-193.

[36] Satomi Y, Shimonishi Y, Hase T, Takao T. Site-specific carbohydrate profiling of human transferrin by nano-flow liquid chromatography/electrospray ionization mass spectrometry. Rapid Commun Mass Spectrom 2004; 18:2983-2988.

[37] Satomi Y, Shimonishi Y, Takao T. N-glycosylation at Asn(491) in the Asn-Xaa-Cys motif of human transferrin. FEBS Lett 2004; 576:51-56. 
[38] Rustad P, Felding P, Franzson L, et al. The Nordic Reference Interval Project 2000:

recommended reference intervals for 25 common biochemical properties. Scand J Clin Lab Invest 2004; 64:271-284. 
Table 1

Data on liver enzymes and transferrin glycoform pattern

\begin{tabular}{llllll}
\hline $\begin{array}{l}\text { Age } \\
\text { (years) }\end{array}$ & $\begin{array}{l}\text { Gender } \\
(\text { Male/Female) }\end{array}$ & $\begin{array}{l}\text { P- } \boldsymbol{\gamma} \mathbf{G T} \\
(\boldsymbol{\mu} \mathbf{k a t} / \mathbf{l})\end{array}$ & $\begin{array}{l}\text { P-ALT } \\
(\boldsymbol{\mu k a t} / \mathbf{l})\end{array}$ & $\begin{array}{l}\text { P-AST } \\
(\boldsymbol{\mu k a t} / \mathbf{l})\end{array}$ & $\begin{array}{l}\text { Transferrin } \\
\text { glycoform pattern }\end{array}$ \\
\hline 67 & $\mathrm{M}$ & $4.6^{*}$ & 0.65 & $1.9^{*}$ & TGP-1 \\
54 & $\mathrm{M}$ & $4.3^{*}$ & 0.36 & 0.50 & TGP-1 \\
36 & $\mathrm{~F}$ & $14^{*}$ & 0.31 & $0.91^{*}$ & TGP-3 \\
67 & $\mathrm{M}$ & $15^{*}$ & 0.46 & $0.84^{*}$ & TGP-1 \\
22 & $\mathrm{M}$ & 0.31 & 0.25 & 0.32 & TGP-2 \\
67 & $\mathrm{M}$ & $5.6^{*}$ & 0.57 & $0.81^{*}$ & TGP-1 \\
48 & $\mathrm{M}$ & $2.8^{*}$ & 0.54 & $1.2^{*}$ & TGP-1 \\
51 & $\mathrm{~F}$ & $7.1^{*}$ & $3.3^{*}$ & $4.6^{*}$ & TGP-1 \\
41 & $\mathrm{M}$ & $4.2^{*}$ & $2.2^{*}$ & $2.6^{*}$ & TGP-1 \\
74 & $\mathrm{~F}$ & $6.9^{*}$ & 0.45 & $0.74^{*}$ & TGP-1 \\
49 & $\mathrm{~F}$ & $10^{*}$ & $1.5^{*}$ & $3.2^{*}$ & TGP-1 \\
51 & $\mathrm{M}$ & $5.3^{*}$ & $2.4^{*}$ & $2.2^{*}$ & TGP-1 \\
39 & $\mathrm{M}$ & $1.6^{*}$ & 0.95 & $0.90^{*}$ & TGP-1 \\
56 & $\mathrm{M}$ & $3.9^{*}$ & $3.2^{*}$ & $2.6^{*}$ & TGP-1 \\
48 & $\mathrm{~F}$ & $14^{*}$ & $1.9^{*}$ & $3.8^{*}$ & TGP-1 \\
38 & $\mathrm{M}$ & 0.34 & 0.27 & 0.44 & TGP-2 \\
61 & $\mathrm{M}$ & $2.6^{*}$ & 0.42 & $1.1^{*}$ & TGP-1 \\
55 & $\mathrm{M}$ & $3.7^{*}$ & 0.38 & 0.54 & TGP-1 \\
23 & $\mathrm{M}$ & 0.60 & 0.51 & 0.39 & TGP-2 \\
\hline
\end{tabular}

*Result above normal reference limit according to NORIP [38] 
Table S1

Gradient profile for analysis of carbohydrate chains by HPAEC-PAD.

\begin{tabular}{|l|l|l|l|}
\hline & Eluent A & Eluent B & Eluent C \\
Time (min) & $\%$ & $(0.2 \mathrm{M} \mathrm{NaOH})$ & $(0.1 \mathrm{M} \mathrm{NaOH}, 0.5 \mathrm{M} \mathrm{NaOAc})$ \\
$\%$ & $\%$ & 1 \\
\hline 0 & 49.5 & 49.5 & 4 \\
\hline 10 & 48 & 48 & 30 \\
\hline 60 & 35 & 35 & \\
\hline
\end{tabular}


Figures captions

Fig. 1

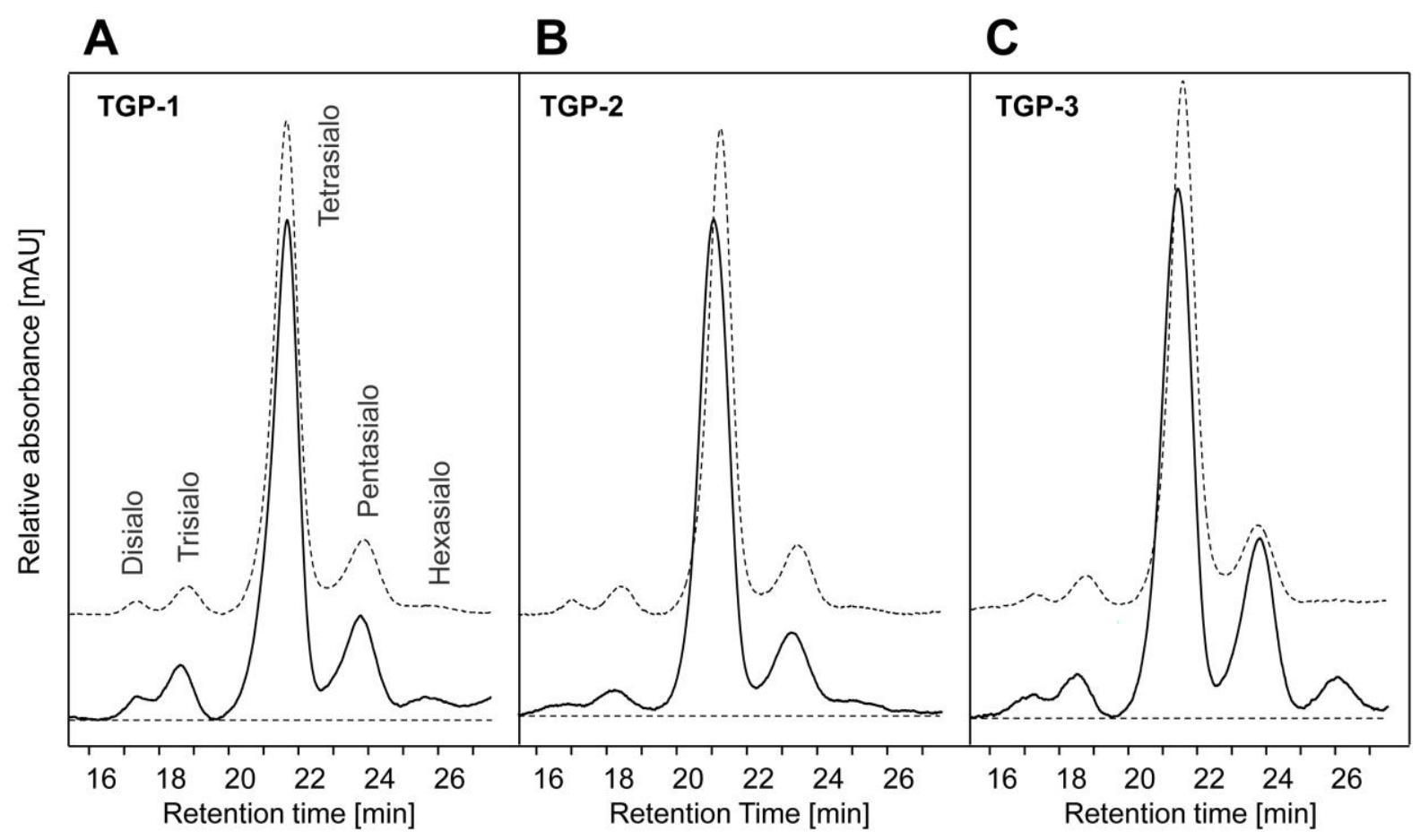

Representative HPLC chromatograms of transferrin glycoforms from patient samples showing di-tri bridging $(-)$ together with an overlay with the control sample run in the same analytical sequence ( --- ). Three different transferrin glycoform patterns were found and denoted TGP-1 (A), TGP-2 (B) and TGP-3 (C). 
Fig. 2A

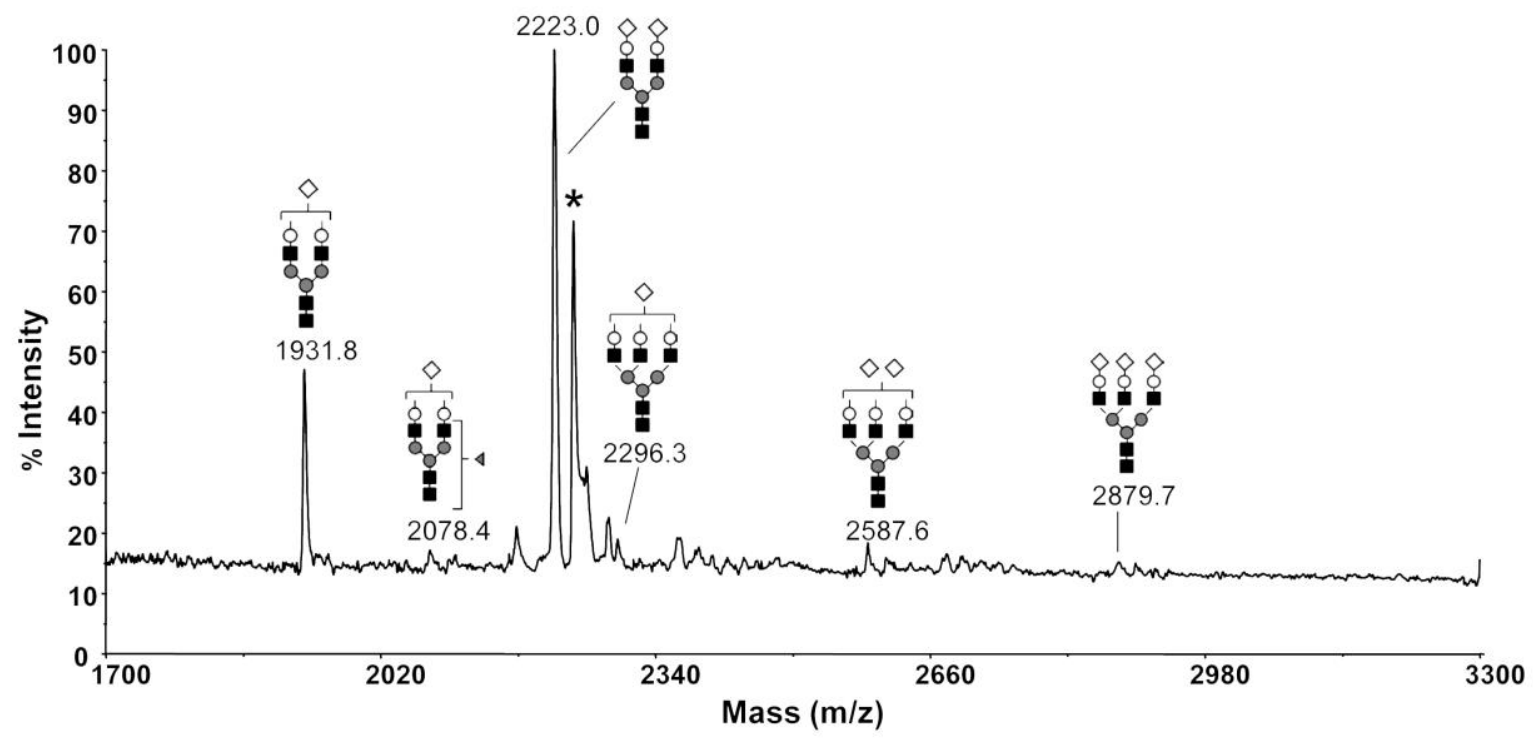

Fig. 2B

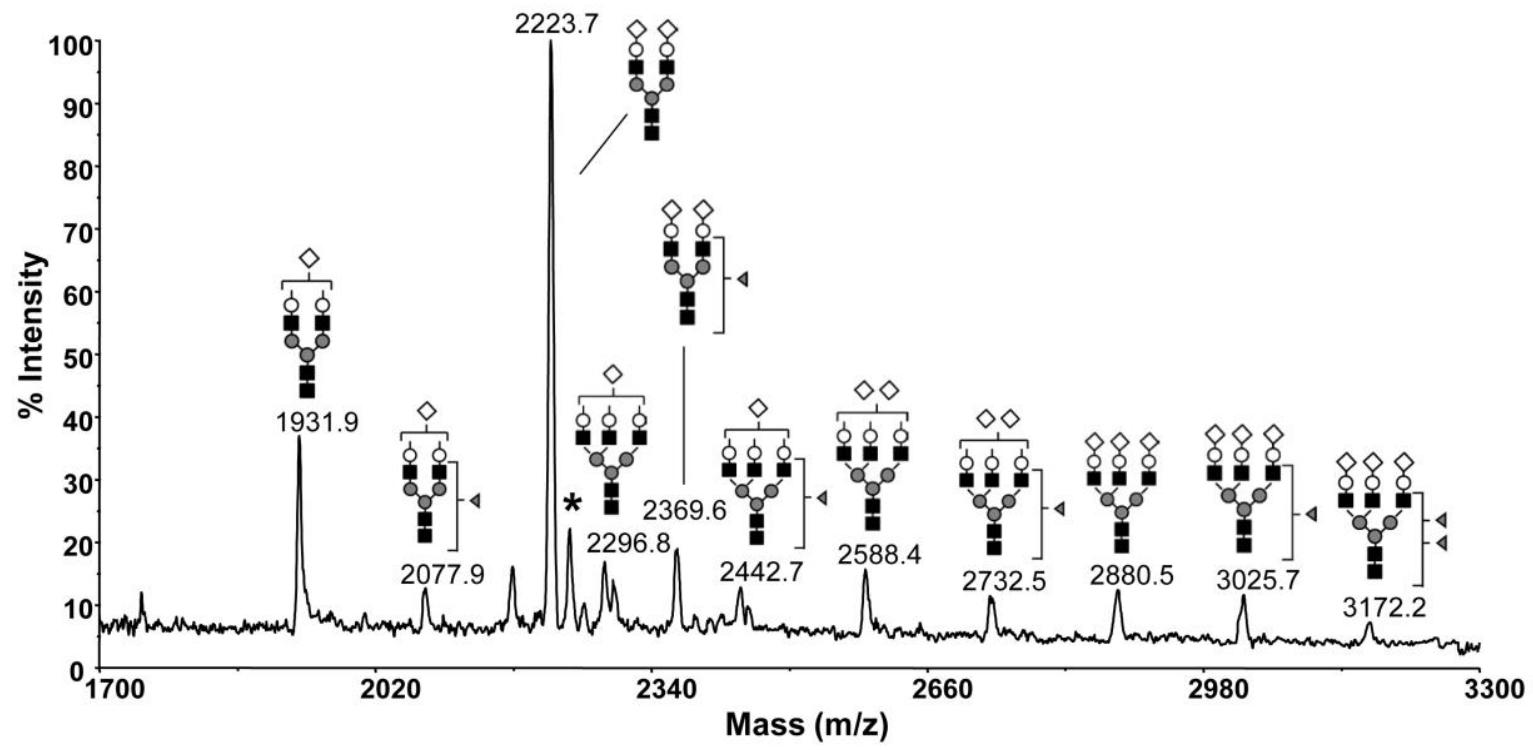


Fig. 2C

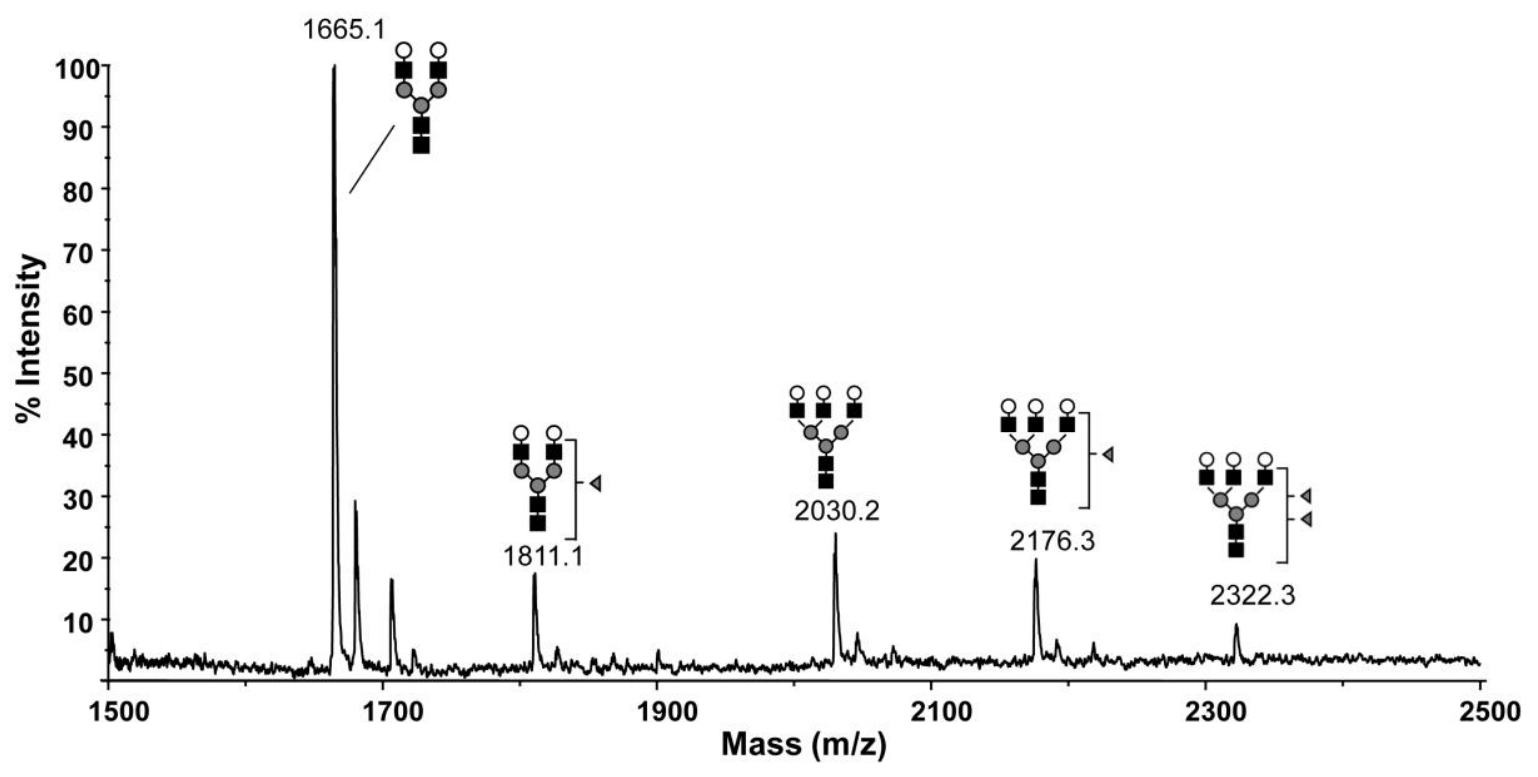

Fig. 2D

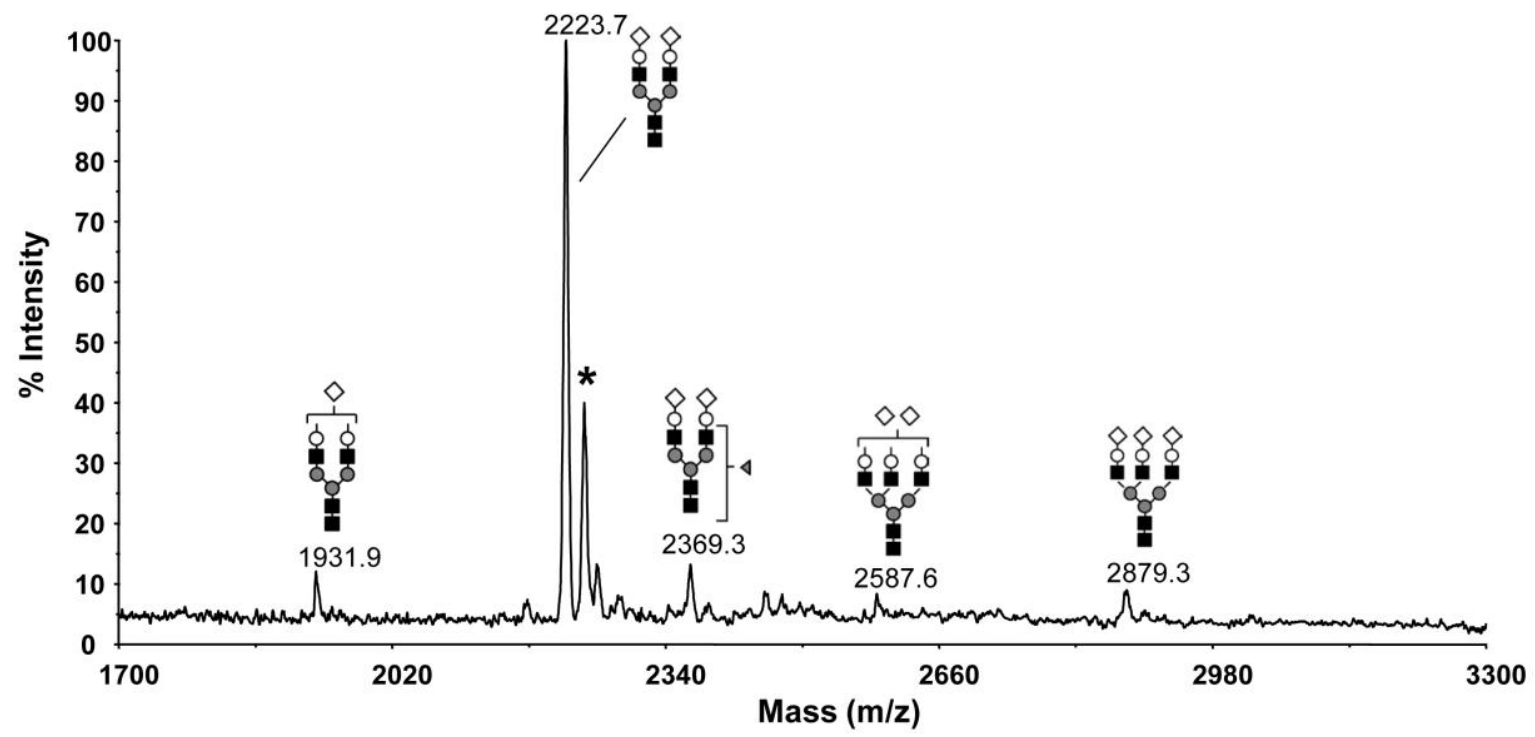


Fig. 2E

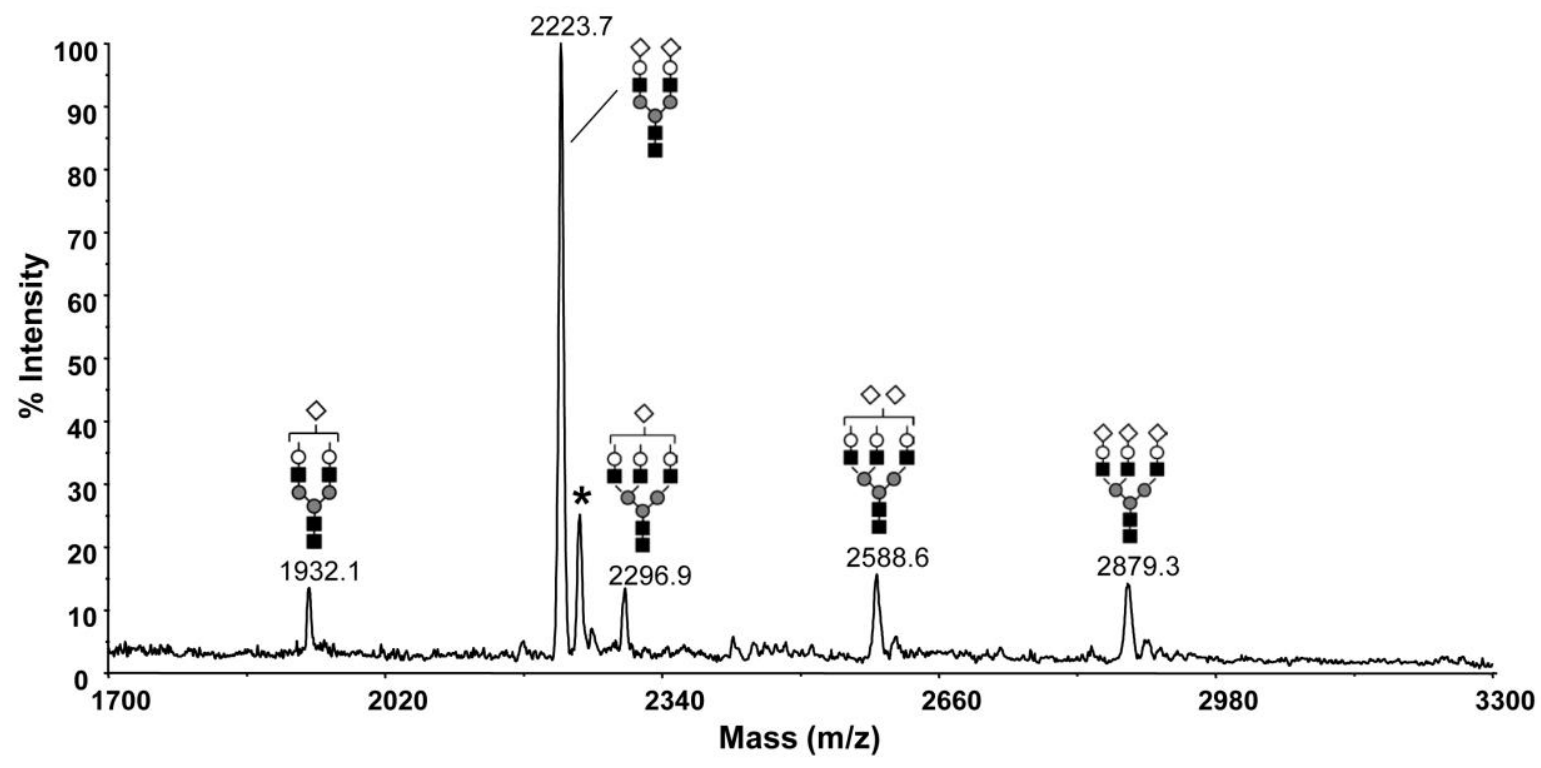

MALDI-TOF mass spectrometry of oligosaccharides released from transferrin. Reference transferrin analyzed in the negative ion-mode (A), a patient sample with TGP-1 di-tri bridging analyzed in the negative ion-mode (B). The indicated $\mathrm{m} / \mathrm{z}$ values represent $[\mathrm{M}-1]$ - ions. A desialylated patient sample with TGP-1 analyzed in the positive ion-mode (C). The indicated $\mathrm{m} / \mathrm{z}$ values represent $[\mathrm{M}+\mathrm{Na}]^{+}$ions. A patient sample with TGP-2 (D) and a patient sample with TGP-3 (E) analyzed in the negative ion-mode. The peak marked with an asterisk (*) in panels A, B, D and E represent the sodium adduct of the disialylated biantennary glycan. Tentative structures are depicted with the following symbols: black (solid) squares, Nacetylglucosamine; grey circles, mannose; open circles, galactose; open rhombi, 5acetylneuraminic acid; grey triangles, fucose. 


\section{Fig. S1}

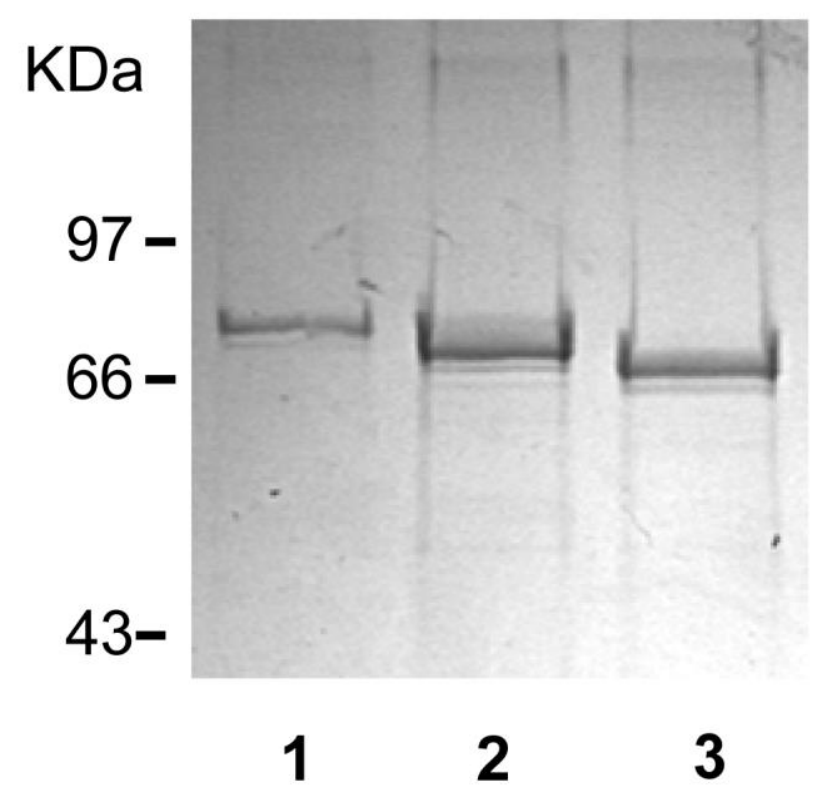

SDS-PAGE of purified transferrin stained with Coomassie blue. Lane 1, affinity purified transferrin from a sample with di-tri bridging; lane 2, non-denatured transferrin after digestion with PNGase F; lane 3, transferrin after denaturation and digestion with PNGase F. The positions of molecular weight markers are indicated to the left. 
Fig.S2A

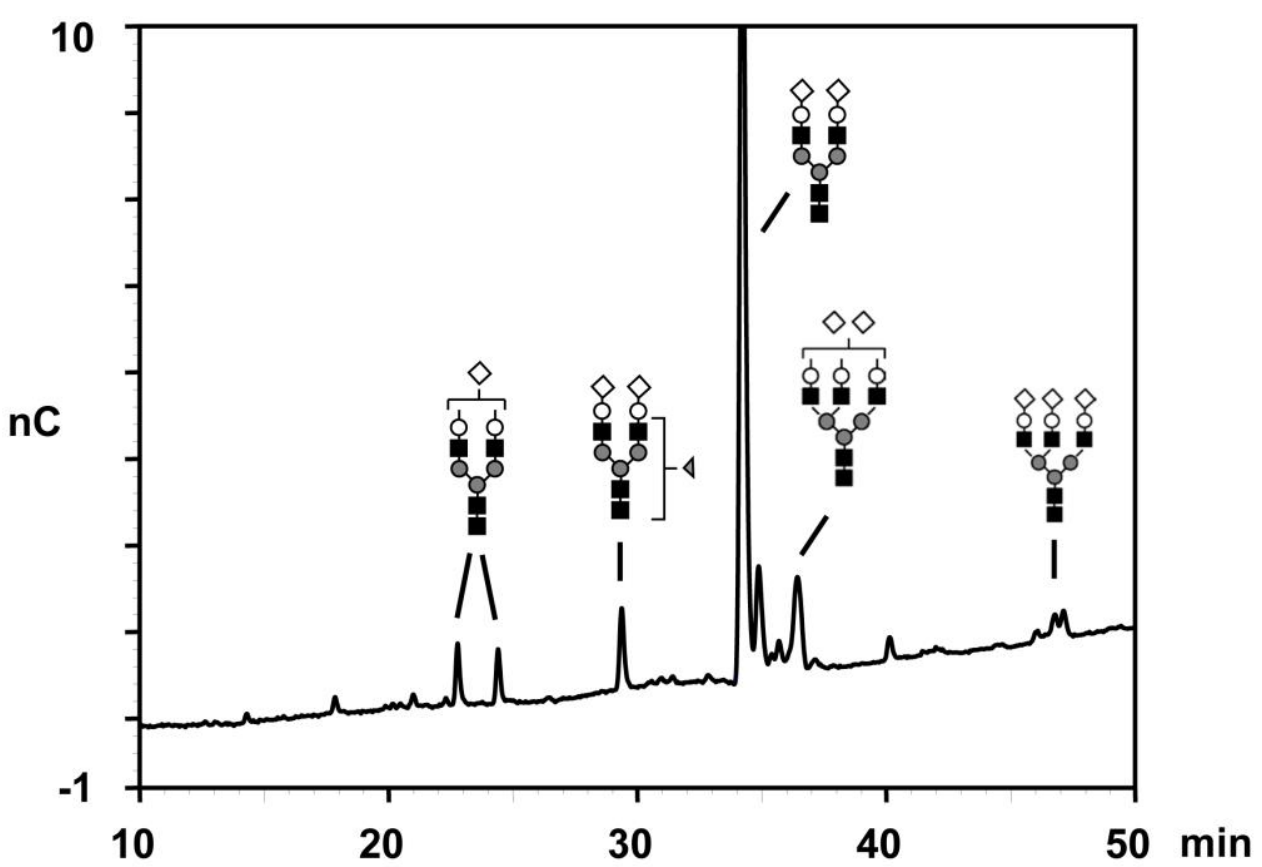

Fig. S2B

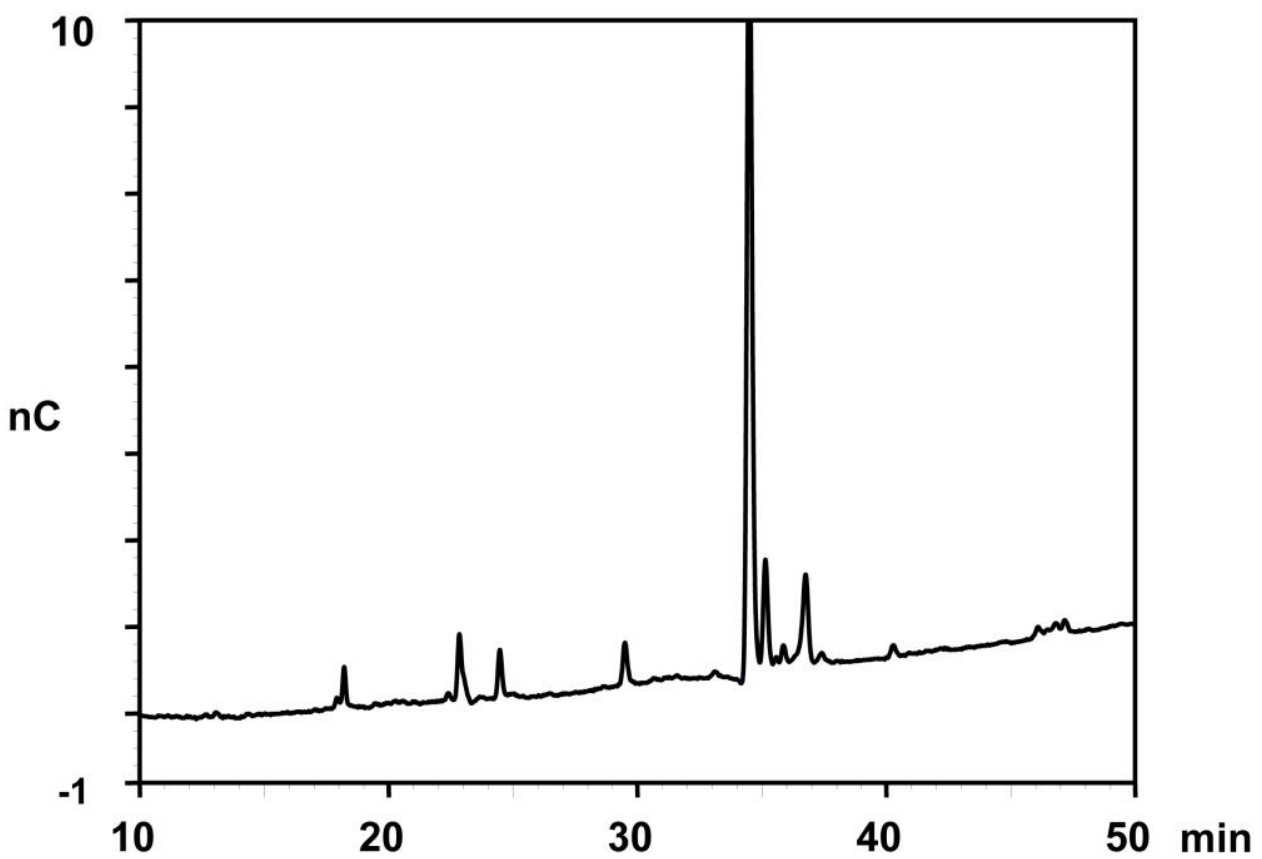


Fig. S2C

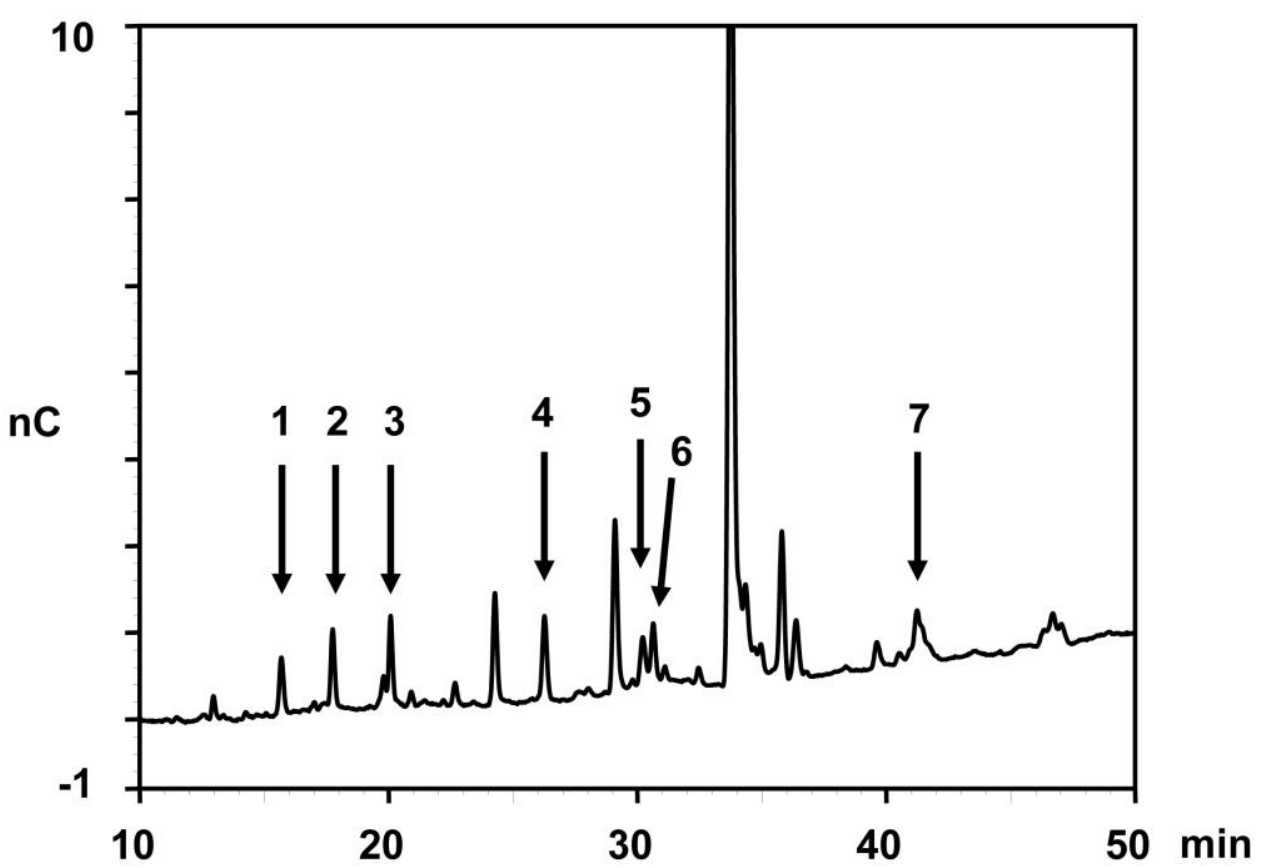

Fig. S2D

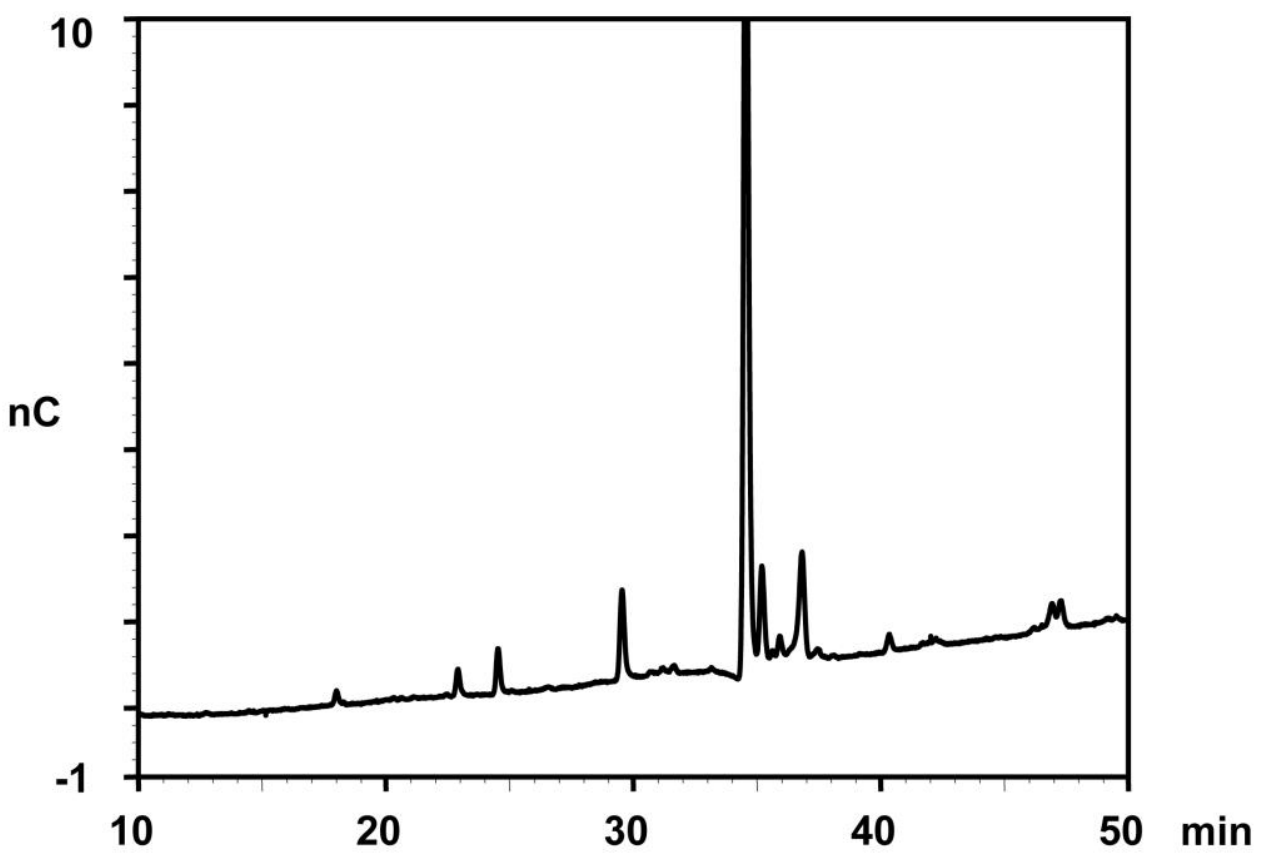


Fig. S2E

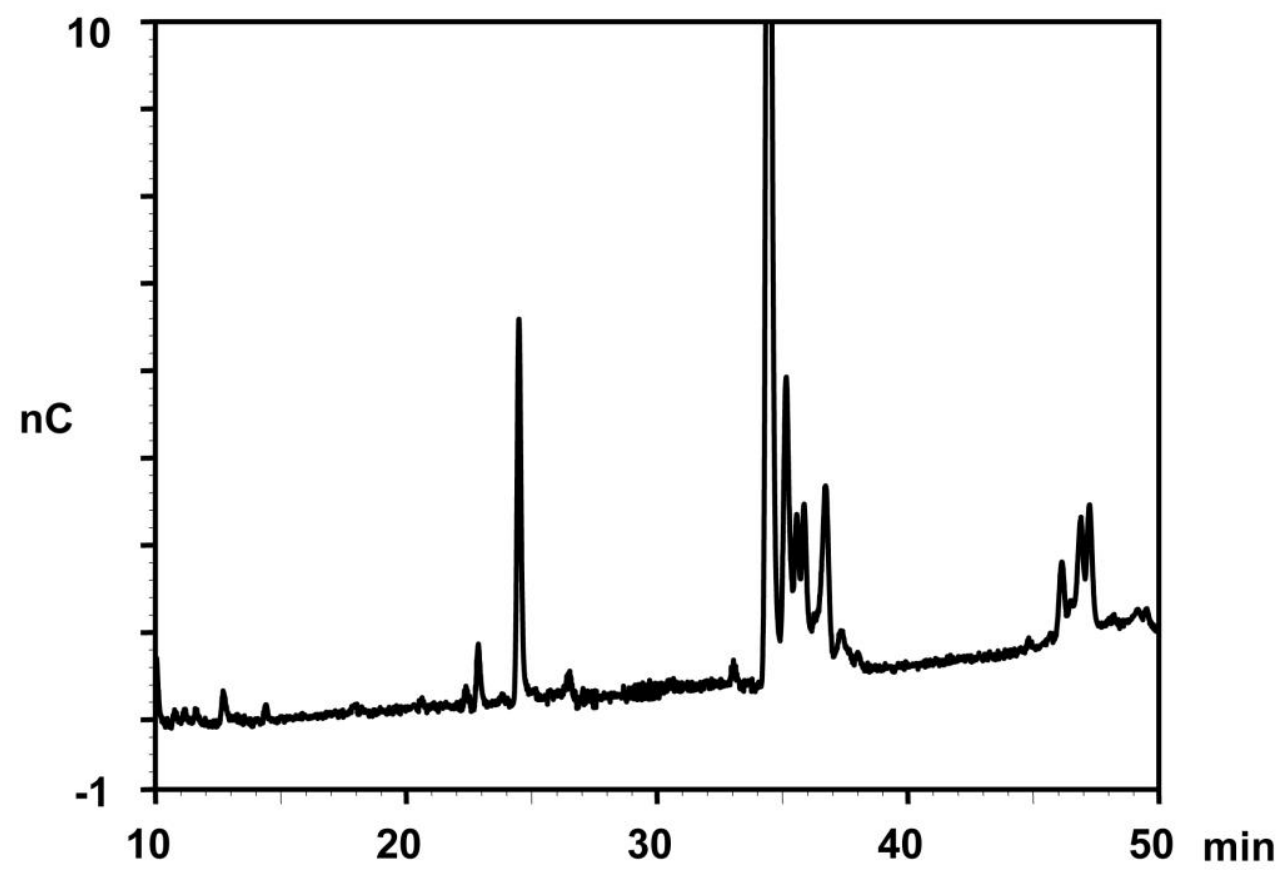

HPAEC-PAD analysis of oligosaccharides released from transferrin. Reference transferrin (A), serum pool from patients with increased CDT but without di-tri bridging (B), a representative chromatogram from a patient with TGP-1 di-tri bridging. Additional peaks compared to reference transferrin are indicated (C), a patient sample with TGP-2 (D) and a patient sample with TGP-3 (E). Tentative structures are depicted with the following symbols: black (solid) squares, $\mathrm{N}$-acetylglucosamine; grey circles, mannose; open circles, galactose; open rhombi, 5-acetylneuraminic acid, grey triangles, fucose. 